\title{
Sustentabilidade na hotelaria
}

\section{Sustainability in the hotel managemant}

\author{
Barbara Fernandes do Nascimento (NASCIMENTO, B. F. do) ${ }^{*}$, \\ Elizabeth Kyoko Wada (WADA, E. K.) ${ }^{* *}$ e \\ Vanuza Bastos Rodrigues (RODRIGUES, V. B.) ${ }^{* * *}$
}

RESUMO - Trabalhar o conceito de sustentabilidade nas empresas pode significar uma grande influência nos resultados que elas desejam alcançar e, também, um importante diferencial no mercado. Por isso, muitos empreendimentos têm adotado esta política e trabalhado a gestão sustentável em seu dia a dia. Nesta pesquisa buscou-se responder a seguinte problemática: "Por que os quesitos ambientais, sociais e econômicos seriam importantes para a gestão de um hotel?". Teve-se por objetivo apresentar a importância de uma gestão sustentável em hotéis, visando ao equilíbrio entre os fatores ambientais, sociais e econômicos para o sucesso do empreendimento, considerando a hospitalidade na relação com os stakeholders para tal. Examinou-se como estava se dando essa gestão sustentável em hotéis, mostrou-se a importância dos stakeholders para esta gestão e procurou-se avaliar como a hospitalidade exerceria influência na relação entre as partes. A pesquisa caracteriza-se como exploratória, empírica e qualitativa. Apresenta-se como um estudo de casos múltiplos, realizado nos hotéis Intercontinental São Paulo, Meliá Jardim Europa e Pullman Ibirapuera localizados na cidade de São Paulo (São Paulo/SP, Brasil). Os resultados obtidos revelaram a importância de se trabalhar a sustentabilidade, considerando os stakeholders para o sucesso dessa gestão.

Palavras-chave: Turismo; Hospitalidade; Serviços; Hotelaria; Sustentabilidade; stakeholders

ABSTRACT - Nowadays, working the concept of the sustainability in companies can have great influence on the results they want to achieve and it can be also a key differentiator in the market. Therefore, many companies have adopted the sustainable management policy. Thus, this research seeks to answer the following question: "Why are the environmental social and economic factors important for the hotel's

\footnotetext{
* Formação: Bacharel em Hotelaria, pela Universidade Anhembi Morumbi. Endereço físico para correspondência: Rua Casa do Ator, 275 - Vila Olímpia. CEP: 04546-001 - São Paulo/SP, Brasil. E-mail: barbara_fernandes_nascimento@hotmail.com

Formação: Bacharel em Turismo pelo Centro Universitário Ibero Americano Unibero e em Comunicação Social - Relações Públicas pela Universidade de São Paulo; Mestrado em Ciências da Comunicação pela Universidade de São Paulo; Doutorado em Ciências da Comunicação pela Universidade de São Paulo; Pós-doutorado em Turismo na Universidade Federal do Paraná. Atividade profissional: Coordenadora do PPG em Hospitalidade da Universidade Anhembi Morumbi (Laureate International Universities). Endereço físico para correspondência: Rua Casa do Ator, 275 - Vila Olímpia. CEP: 04546-001 - São Paulo/SP, Brasil. E-mail: ewada@uol.com.br

Formação: Bacharel em Biblioteconomia pela Escola da Ciência da Informação da Universidade Federal de Minas Gerais; Mestrado em Administração pelo Centro Universitário Unihorizontes; Doutoranda no Programa de Pós-Graduação Stricto Senso em Hospitalidade da Universidade Anhembi Morumbi. Endereço físico para correspondência: Rua Casa do Ator, 275 - Vila Olímpia. CEP: 04546-001 - São Paulo/SP, Brasil. E-mail: vanuzabastos@bol.com.br
} 
management?" The main goal of this study is to present the importance of sustainable management intending the balance between environmental, social and economic factors for the success of the company, considering the hospitality in the relationship with stakeholders for such. It was examined how is that sustainable management in hotels, how important the stakeholders are for this management, in addition to evaluating as hospitality influences the relationship between the parties. The research is characterized as exploratory, empirical and qualitative. It is presented as a multiple case study in the hotels Intercontinental São Paulo, Meliá Jardim Europa and Pullman Ibirapuera. The results show the importance of working current sustainability, considering the stakeholders to the success of this management.

Key words: Tourism; Hospitality; Services; Sustainability; Hotel management; stakeholders. 


\section{INTRODUÇÃO}

Trabalhar a sustentabilidade no contexto atual de globalização "passou a ser um grande fator estratégico de competitividade para as empresas que escolheram trabalhar seus negócios com a gestão ambiental" (GONÇALVES, 2004, p. 16) e, consequentemente, com a sustentabilidade como um todo, englobando os fatores econômicos e a responsabilidade social em seu trabalho e suas ações para com o meio ambiente.

Nesta pesquisa teve-se por objetivo geral apresentar a importância de uma gestão sustentável, visando ao equilíbrio entre os fatores ambientais, sociais e econômicos para o sucesso de um empreendimento, considerando a hospitalidade na relação com os stakeholders para tal. Citam-se como objetivos específicos: examinar a gestão sustentável em hotéis; analisar a importância dos atores para esta gestão; e avaliar como a hospitalidade influenciaria a relação entre as partes. Diante do contexto apresentado, foi elaborada a seguinte problemática: Por que os quesitos ambientais, sociais e econômicos seriam importantes para a gestão de um hotel?

\section{REFERENCIAL TEÓRICO}

Neste referencial teórico se tem uma abordagem sobre conceitos de hospitalidade, os campos de estudo e serviços na hotelaria.

\subsection{CONCEITOS SOBRE HOSPITALIDADE}

A palavra "hospitalidade" abrange o ato de hospedar e acolher. Porém, o tema traz maiores e diversas implicações. A hospitalidade se faz presente em inúmeros lugares: casas familiares, hospitais, comércios, empresas e, até, em sites e páginas online. Apesar de abarcar áreas distintas, a hospitalidade, em todos os locais, tem algo em comum: parte do relacionamento humano.

Em sua obra, Camargo (2004) apresenta a hospitalidade como a relação entre dar, receber e retribuir. Começa a partir de uma dádiva, que "desencadeia o processo de 
hospitalidade, seja ou não precedida de um pedido de ajuda, numa perspectiva de reforço do vínculo social" (CAMARGO, 2004, p. 19). Acarreta alguns sacrifícios e pode trazer consigo interesses, como o de ser nobre. De outro lado, o ato leva a uma sensação de inferioridade para quem recebe, além da obrigação da retribuição.

Abreu (2003, p. 29) explica que "a hospitalidade pode ser definida como sendo o atributo ou característica que permite aos indivíduos de famílias e lugares diferentes se relacionar socialmente, se alojar e prestar serviços reciprocamente".

\subsection{CAMPOS DE ESTUDO}

Camargo (2004) apresenta a hospitalidade em dois eixos: cultural, que engloba os atos de receber, hospedar, alimentar e entreter; e o social, que se categoriza como sendo: doméstica ou privada, pública ou social, comercial e virtual.

Entende-se o ato de receber como pioneiro da hospitalidade. Contempla os atos de recepcionar e acolher as pessoas em casa. Por hospedar entende-se como sendo o ato de proporcionar abrigo a alguém necessitado. Já por alimentar entende-se como o ato de oferecer alimento. "Em algumas culturas, a oferta de alimento delimita e concretiza o ato de hospitalidade, ainda que esse alimento seja simbólico, sob a forma de um copo com água ou do pão que se reparte em algumas culturas" (CAMARGO, 2004, p. 15).

A hospitalidade, seja no eixo privado ou doméstico, é o ato mais tradicional, presente desde os tempos antigos. Contempla receber pessoas em seu próprio lar e a relação entre hóspede e anfitrião, o bem receber e o acolhimento. Lashley e Morrison (2004, p. 14) afirmam que "o cenário doméstico de oferta de hospitalidade pode ser o foro para o inter-relacionamento entre os espaços doméstico e social”. Enquanto pública ou social, a hospitalidade pode ser definida, segundo Camargo (2004, p. 54) como sendo:

[...] hospitalidade que acontece em decorrência do direito de ir-e-vir e, em consequência, de ser atendido em suas expectativas de interação humana, podendo ser entendida tanto no cotidiano da vida urbana que privilegia os residentes, como na dimensão turística e na dimensão política mais ampla - a problemática dos migrantes de países mais pobres em direção aos mais ricos.

A hospitalidade vem, desde os tempos antigos, ligada a questões religiosas, sendo vista como obrigação por todos os cidadãos. É também vista como dever de 
órgãos públicos em lugares como: hospitais, prisões, creches e escolas. Além disso, pode se entender por hospitalidade pública os serviços disponibilizados à população, como saneamento básico, coleta de lixo e energia elétrica. A estrutura de uma cidade tem forte influência na avaliação de hospitalidade dos turistas e visitantes. Ensinam Lashley e Morrison (2004, p. 9): "o dever de ser não só generoso, em relação ao forasteiro, mas também protetor é um importante aspecto desse filão de hospitalidade". A hospitalidade no campo comercial abrange a relação entre cliente e profissional estabelecida em uma prestação de serviços de hospedagem, alimentação ou comércio em geral com a obrigação de um acolhimento cortês e gentil (YASSUDA, 2004, p. 20). Dentro de um comércio, a qualidade do atendimento, ou o grau de atenção oferecido pelo profissional, pode influenciar o comportamento do cliente no sentido de continuar ou não a frequentá-lo (SILVA, 2012). Logo: "para ser eficaz é preciso que o hóspede sinta que o anfitrião está sendo hospitaleiro por sentimento de generosidade, pelo desejo de agradar e por ver a ele, hóspede, enquanto indivíduo" (LASHLEY; MORRISON, 2004, p. 24). Pode-se entender a hospitalidade em âmbito virtual como sendo a hospitalidade presente na internet, sites de empresas, sites de órgãos públicos, sites de cidades ou, até mesmo, entre um indivíduo e na relação entre acolhedor (site) e o acolhido (internauta), integrados por uma mídia social. A explosão da internet na vida de todos é visível. Por se tratar de um campo novo, o quesito virtual é indispensável para a realização de estudos sobre hospitalidade, conforme Camargo (2004, p. 18): “a inclusão da hospitalidade virtual [...] em sites na Internet de empresas, cidades, órgãos públicos, indivíduos etc. mostram uma tendência de tal forma ascensional que é difícil imaginar o futuro da hospitalidade sem uma consideração desse campo virtual”.

Considera-se a hospitalidade na hotelaria como sendo a hospitalidade em âmbito comercial, por se tratar de uma prestação de serviço que é cobrada do hóspede pelo anfitrião (hotel) e por ter como característica a relação entre eles.

Ao contrário do que se costuma pensar, a hotelaria e hospitalidade não são a mesma coisa. Um profissional de hospitalidade se diferencia de um profissional da hotelaria, pois a hospitalidade abrange o ato de receber em diferentes lugares $\mathrm{e}$ situações. Não obrigatoriamente em hotéis (GUIZI; SANTOS; WADA, 2014). Assim, a percepção de hospitalidade dos hóspedes não se resume somente às "boas-vindas" da equipe de recepção, mas, sim, a toda infraestrutura e qualidade das instalações e 
serviços que forem usufruídos por eles durante sua estada. Todos os itens citados acima são fatores que, além de gerar melhor posicionamento para o hotel, podem acarretar recomendações para demais possíveis clientes - marketing mais conhecido como propaganda "boca a boca" (GUIZI; SANTOS; WADA, 2014).

Apesar de trabalhada principalmente na prestação de serviços, a hospitalidade não deve ser direcionada exclusivamente aos clientes. "O diferencial competitivo da excelência no setor de serviços não é algo inato à atividade, e sim adquirido e conquistado. Sua manutenção é fundamental para fomentar o empreendimento no segmento" (QUADROS, 2011, p. XX).

Por isso, a hospitalidade deve ser trabalhada primeiramente com os funcionários. Afinal, são eles que acolhem e devem ser hospitaleiros com os hóspedes. Ou, melhor dizendo, fazem o contato direto com eles. Esclarece Bekin (2004, p. 140): “as empresas que satisfazerem seus clientes internos serão as com maior chance de terem clientes também satisfeitos".

Para os meios de hospedagem, a hospitalidade oferecida aos hóspedes é essencial. Daí a maneira como os serviços são executados terem grande influência na satisfação deles.

\subsection{SERVIÇOS NA HOTELARIA}

Os empreendimentos que trabalham com a prestação de serviços e buscam sua melhor execução devem se manter constantemente atentos à avaliação de seus clientes, para saber como está o seu desempenho. Assim, fazer uso da hospitalidade pode garantir o sucesso do empreendimento.

De acordo com o Serviço de Brasileiro de Apoio às Micro e Pequenas Empresas (SEBRAE, 2000, p. 19), "a qualidade é inerente ao produto ou serviço, mas é julgada pelo cliente". Para Albrecht (1994), a qualidade dos serviços prestados aos clientes é um forte diferencial competitivo e não depende apenas de uma pessoa da empresa, mas, sim, de todos os colaboradores que trabalham em conjunto para melhor atender e satisfazer seus clientes. Albrecht (1994) defende a ideia de que os colaboradores devem ver seus serviços no ponto de vista do cliente, para assim, tentar satisfazer suas necessidades. 
Para que exista uma prestação de serviços eficaz, o hotel precisa que seus funcionários estejam treinados e atentos para agradarem e oferecerem a hospitalidade necessária a seus hóspedes. O funcionário, por sua vez, oferece hospitalidade de acordo com o tratamento que recebe de seus líderes. Portanto, entender o conceito de stakeholder e a importância de trabalhá-lo é imprescindível, como será mostrado a seguir.

\section{CONCEITOS SOBRE STAKEHOLDERS}

Para melhor entendimento sobre stakeholders, é aconselhável recorrer à Freeman (1984, p. 5), que apresenta a teoria de que stakeholders são "todos os indivíduos, grupo ou organizações que são afetados ou afetam outros stakeholders para alcançar o objetivo de uma determinada empresa". Com isso, pode-se considerar como stakeholder tanto quem investe financeiramente no empreendimento como o funcionário que cumpre suas obrigações e desempenha um bom trabalho, além do grupo de pessoas que "sofre as consequências das ações organizacionais (como o grupo de moradores de uma região)". (KOGA; WADA, 2013). Ao ignorarem essas influências, algumas empresas foram devastadas ou chegaram à falência (TAPSCOTT; TICOLL, 2005). Assim, é necessário identificar cada um desses possíveis grupos e qual maneira de trabalhar com eles.

O conceito de stakeholders teve seu início na análise de um modelo de negócio antigo que consistia, basicamente, na compra da matéria-prima de fornecedores, convertendo-as em produtos para então vendê-la. Ao longo do tempo, este modelo mudou, passando a exigir uma nova adaptação para a criação de um "modelo conceitual". De acordo com Freeman (1984, p. 5), as empresas familiares foram se modificando e começaram a se tornar mais profissionalizadas, além de terem maiores acessos a novas tecnologias e novos processos de produção e montagem, ajudando, assim, na criação de projetos e produtos. Porém, esse modelo gerencial não se atentava aos fatores externos da organização, o que dificultava o alcance de algumas de suas metas. Por isso, Freeman (1984) explica que é preciso que os gerentes se atentem a 
todos os grupos (internos ou externos) que, de alguma maneira, influenciam e/ou são influenciados nos procedimentos e nas tomadas de decisões da empresa.

A partir daí, Freeman (1984) criou uma categorização para os stakeholders, a fim de proporcionar aos empreendimentos melhor análise para gestão. As empresas poderiam saber em quem depositar atenção e em determinado momento, para obterem melhores resultados. Os stakeholders foram então categorizados em dois grupos: pela influência interna, sendo eles fornecedores, investidores, financiadores, acionistas, clientes, funcionários, sindicatos e clientes; e outro por sua influência externa, sendo eles o governo, a concorrência e a comunidade local.

Clarkson (1995, p. 106) categorizou os stakeholders em: primários - aqueles cujo interesse e participação são imprescindíveis para a empresa, citando-se os acionistas e investidores, funcionários, fornecedores, consumidores, governo e a comunidade; e secundários - aqueles que não fazem parte das transações da empresa e não são de suma importância para ela, mas que podem fazer a diferença em um dado momento, citando-se a mídia e outros grupos específicos.

\title{
3.1 A SUSTENTABILIDADE NA HOTELARIA
}

As empresas precisam trabalhar seus objetivos econômicos e financeiros juntamente com problemas relacionados ao meio ambiente e a questões sociais. "Aos olhos da sociedade, a conduta socialmente relevante vem sendo percebida como decisiva para definir prognósticos de sucesso ou fracasso empresarial" (LYRA; GOMES; JACOVINE, 2009).

Silva (2012, p. 61) explica:

\begin{abstract}
O conceito de sustentabilidade representa para o setor empresarial uma nova abordagem de se fazer negócios que promove a responsabilidade social, reduz o uso de recursos naturais, reduzindo consequentemente, os impactos negativos sobre o meio ambiente, preservando a integridade do planeta para as futuras gerações, sem deixar de lado a rentabilidade econômico-financeira do empreendimento.
\end{abstract}

Portanto, a sustentabilidade empresarial pode ser apresentada com um novo conceito para as empresas, o qual pode gerar a captação de valor aos acionistas ao longo dos anos, partindo de ações como a captação de novos investidores a partir da 
divulgação da gestão empresarial, aliada às ações de responsabilidade social e ambiental. Essas duas, se trabalhadas juntamente com a gestão econômica, poderão trazer benefícios às organizações (ANDRADE, 2012, p. 25).

É comum ouvir a palavra "sustentabilidade". Seu conceito é caracterizado por ser sistêmico. Ou melhor, trata-se do relacionamento entre aspectos econômicos, sociais e ambientais da sociedade. "A palavra-chave é a continuidade - como essas vertentes podem se manter em equilíbrio ao longo do tempo" (CABRERA, 2009). De acordo com o autor, o termo "sustentabilidade" surgiu em 1997, usado pela norueguesa GroBrundtland, ex-primeira ministra, que na época era presidente de uma comissão da Organização das Nações Unidas. Ela publicou um livreto cujo título era Our Common Future $^{1}$, que tratava da relação entre meio ambiente e progresso, no qual explicava que o desenvolvimento sustentável parte do conceito de suprir as necessidades do presente sem afetar as necessidades futuras. "Essa definição deixa claro um dos princípios básicos de sustentabilidade, a visão de longo prazo, uma vez que os interesses das futuras gerações devem ser analisados" (CLARO; CLARO; AMÂNCIO, 2008). O risco referente aos fatores econômicos, sociais e ambientais tomou grandes proporções e fez com que a comunidade internacional tomasse providências para desenvolver alternativas e criar um modelo de desenvolvimento para as nações, buscando o crescimento no longo prazo. Assim, foram feitas diversas reuniões para buscar tais alternativas.

Claro, Claro e Amâncio (2008, p. 290) explicam a dimensão econômica como sendo responsável não somente pelo lucro em si, mas também pelas “atividades informais que provêm serviços para os indivíduos e grupos e aumentam, assim, a renda monetária e o padrão de vida dos indivíduos”. A dimensão ecológica, ou ambiental, engloba o estímulo das empresas que visam à diminuição de seus impactos no meio ambiente e os inserem em sua rotina e procedimentos de administração ambiental. Por fim, a dimensão social engloba qualidades dos seres humanos, tais como, habilidades e experiências, tanto internas como externas à empresa.

O conceito de sustentabilidade é passado pelos gestores e empreendedores aos seus funcionários, consumidores, concorrentes, parceiros, Organizações NãoGovernamentais (ONGs) e as organizações governamentais e busca atrelar práticas

\footnotetext{
${ }^{1}$ World Commission on Environment and Development. Our common future. Report to United Nations General Assembly. Oxford and New York: Oxford University Press, 1987.
} 
sustentáveis à imagem da empresa. Porém, muitos empreendimentos não associam corretamente seu conceito de sustentabilidade às práticas em si. Eles focam unicamente a questão social, ou somente as questões ambientais, ou, como é comum acontecer, unicamente nas questões econômicas (CLARO; CLARO; AMÂNCIO, 2008).

A busca por uma administração sustentável muda o comportamento das empresas, pois os problemas ambientais, sociais e econômicos estão frequentes no mundo todo. Com isso, a pressão por parte da sociedade via movimentos sociais reivindicatórios é grande, e o movimento traz a elaboração de novas leis. Tais mudanças influenciam os empreendimentos a inovarem seus procedimentos para que sejam executados de forma eficaz e que exceda as expectativas sociais e ambientais, além da financeira (CLARO; CLARO; AMÂNCIO, 2008).

De acordo com Seiffert (2007, p. 17), “a relação do ser humano com o seu meio ambiente apresenta imediatamente a questão de como ele constrói as suas condições de vida, as quais são reflexos das opções econômicas adotadas". Para ela, a qualidade de vida de um indivíduo é reflexo da qualidade ambiental em que está inserido. Assim, a "relação entre a qualidade ambiental e o desenvolvimento se dá pela busca do crescimento econômico" (ANDRADE, 2012, p. 29).

Gonçalves (2004) afirma que a sociedade tem mostrado preocupação e está mais atenta a essa degradação, passando a exigir das empresas novos procedimentos (legais e gerenciais) que respeitem tanto a sociedade quanto o meio ambiente.

Segundo Vieira e Hoffmann (2007), o século XX, mais precisamente os anos 1970, foi marcado pela ideia de qualidade no meio ambiente, com destaque para o produto turístico. Os autores completam afirmando que no segmento hoteleiro, essa ideia de qualidade no meio ambiente teve início nos anos de 1990, a partir de um novo conceito de construção dos prédios e na maneira em que suas atividades eram operadas.

Atrelado a esta ideia, Gonçalves (2004, p. 16) afirma que "a boa imagem da organização no contexto da crescente globalização dos mercados passa a ser fator estratégico de competitividade, tornando-se fundamental para as empresas aliarem seus processos de negócios à gestão ambiental".

Entretanto, a ideia de implantação de ações que visem à diminuição de produção de lixo e à redução de emissões, além da diminuição do consumo de água e consumo de energia, entre outras ações, está atrelada à mudança no processo e à mudança dos 
materiais. Inclui-se o fato de que os hotéis estão propensos ao desperdício, porque o consumo de água ou energia, por exemplo, foge da administração dos gestores. Afinal, o consumo é gerenciado pelos próprios hóspedes e funcionários. Por isso, o fator mais importante para o alcance dos resultados está na mudança de hábito das pessoas. (VIEIRA, 2007).

A questão social envolve todo o capital humano de uma sociedade. Em se tratando de um empreendimento, a sustentabilidade social não abrange somente salários justos e o cumprimento das legislações trabalhistas para os funcionários, mas também o bem-estar de cada um dos trabalhadores. Além disso, é preciso observar como a atividade econômica do seu empreendimento afeta a comunidade local.

A sustentabilidade econômica refere-se às práticas do empreendimento para alcançar seus objetivos financeiros. Segundo Andrade (2012, p. 29), “a sustentabilidade econômica [...] comporta as diversidades das atividades de produção, em todo seu processo, desempenhando um equilíbrio no desenvolvimento econômico".

\section{METODOLOGIA}

Esta pesquisa caracteriza-se como exploratória, de caráter empírico e qualitativo. Foi desenvolvida a partir de um levantamento bibliográfico e da preparação do referencial teórico, nas áreas de hospitalidade, serviços, hotelaria, sustentabilidade e stakeholders. Para a elaboração do estudo de casos múltiplos, contou-se com a seleção de três objetos de estudo, escolhidos por conveniência, seguindo o protocolo proposto por Yin (2005), que considera sua caracterização, a partir do referencial teórico e das proposições, com base na análise de conteúdo proposta por Bardin (1977), para a realização de um roteiro de entrevista para o primeiro participante da pesquisa.

Para tanto, foram estabelecidas três proposições: a) A implantação de uma gestão sustentável traz lucro; b) A gestão sustentável contempla o cuidado com os stakeholders; e c) A hospitalidade contribui na relação positiva com os stakeholders.

Nas entrevistas, foi utilizado o método de bola de neve para a realização das demais entrevistas, a partir da apresentação de um mapa de stakeholder, com fundamento em Freeman (1984), elaborado pelas autoras. Foi feito um novo roteiro para 
entrevistas com os stakeholders indicados, para verificar como se dava o relacionamento entre hotel e stakeholder. Foram realizadas sete entrevistas, de acordo com a disponibilidade de cada gestor e seus indicados. E, por fim, foi feita a transcrição das entrevistas realizadas, com a eliminação de erros gramaticais e vícios de linguagem, para a análise dos dados obtidos, visando confrontar com as proposições, a partir do conteúdo da categorização.

\section{ANÁLISE DE DADOS}

Apresenta-se a seguir os resultados obtidos com as entrevistas realizadas. Destaca-se que todos os entrevistados assinaram o "termo de livre consentimento" autorizando a divulgação dos seus sobrenomes.

\subsection{PROPOSIÇÃO 1: A IMPLANTAÇÃO DE UMA GESTÃO SUSTENTÁVEL TRAZ LUCRO}

Esta proposição foi parcialmente ratificada, com base nos depoimentos coletados durantes as entrevistas com os gerentes e seus stakeholders. Foi enfatizado o fato de que ser um hotel que trabalhava com ações voltadas à sustentabilidade poderia ser um fator decisório para os negócios da empresa. Porém, alguns gestores mencionaram acreditar que o preço ainda fosse o principal fator para a tomada de decisão dos clientes.

No hotel Pullman Ibirapuera, a governanta, disse que "hoje [os clientes] exigem verificar toda a parte de sustentabilidade antes de fechamento de contrato. Tem cliente que fala 'o que vocês fazem de sustentabilidade?'” Tem empresa que foca muito isso, eles querem ver, querem marcar visita para poder verificar".

De acordo com Miranda:

Os grandes clientes, principalmente os de eventos, têm esse questionamento, e é um diferencial quando você manda a sua proposta em que na nossa proposta já é mencionado algo sobre o nosso programa do Planet 21 e nesse questionamento acaba sendo um dos pontos decisivos para fechar o contrato ou não. Principalmente para eventos que a gente vê que vão gerar um volume muito grande de lixo. 
A supervisora de qualidade do Meliá Jardim Europa, destacou que havia hóspedes que escolhiam o hotel justamente pelo fato de terem um andar voltado à sustentabilidade.

Lyra, Gomes e Jocovine (2009) dão fundamento aos depoimentos quando afirmam que vem se utilizando dos fatores socialmente relevantes, e isso define o sucesso ou fracasso das empresas. Peres e Rezende (2011) afirmam que as empresas devem implantar uma eficiente gestão de sustentabilidade para se adequar, não somente às questões legais, como também à nova postura dos consumidores, que se preocupam com o planeta, para poder aproveitar as oportunidades de negócios que podem ser geradas. $\mathrm{O}$ consumidor está muito mais atento às questões sociais e ambientais e têm exigido isso das empresas (GONÇALVES, 2004).

A gerente de compras do Intercontinental São Paulo, mencionou acreditar que ser um hotel sustentável ainda "está se tornando [um diferencial]. Não tenho certeza ainda se um hóspede vai optar ou não por um hotel sustentável hoje em dia" (BETTINI).

Ela ofereceu a seguinte ideia:

\footnotetext{
Pessoalmente, no Brasil, acho que o consumidor não se preocupa muito, o que a gente ouve muito dos associados e aí principalmente do pessoal do comercial, é que na hora de fazer as RFP'S, quando as empresas mandam essas demandas de hospedagem para as redes cada vez mais elas colocam aquelas perguntinhas de que se a sua empresa tem uma política de sustentabilidade, se a sua empresa faz... Mas o feeling de quem trabalha nas redes é de que você respondendo sim ou não o gestor vai se importar mesmo com o preço da sua diária (BETTINI).
}

Silva acrescentou: "Eu acho que poucas pessoas vão fazer uma escolha com a relação de ser um hotel sustentável". E reconheceu que "[...] hoje eu acho que a cultura, as pessoas não veem isso como um diferencial. Tem pessoas que sim, mas são poucas, acho que dentro de uma margem, são poucas".

Gonzaga ainda definiu que poderia ser um fator decisório, uma vez que a empresa que buscava fechar um negócio com o hotel também possuía uma estratégia voltada à sustentabilidade.

Em se tratando de redução de custos, Batista (2015) afirmou: 
É um diferencial se for pensar pelo lado financeiro, se a gente consegue produzir menos, precisar de menos produto, a gente vai gastar menos dinheiro com isso então a gente pode utilizar esse dinheiro para fazer melhorias dentro do hotel e assim, tornar isso um fator de competitividade.

De acordo com Gonzaga, em consumo de água e energia, por exemplo, há redução. Porém, diante do contexto atual, não se estava percebendo uma redução no valor final.

\subsection{PROPOSIÇÃO 2: A GESTÃO SUSTENTÁVEL CONTEMPLA O CUIDADO NA RELAÇÃO COM OS STAKEHOLDERS.}

Esta proposição foi ratificada. Em se tratando do relacionamento entre o hotel e seus stakeholders, sendo eles, principalmente, funcionários, fornecedores e os hóspedes. Foi analisado como a gestão sustentável influenciava o relacionamento entre as partes.

Nas entrevistas, foi possível perceber o comprometimento dos funcionários com as ações do hotel, a busca por fornecedores que também tivessem suas ações voltadas à sustentabilidade e, em contrapartida, como os clientes também buscavam os hotéis que trabalhassem da mesma forma, além de conhecer como era feita a comunicação das ações de cada hotel com seus hóspedes.

Para Freeman (1984), stakeholder é qualquer um que afete ou que seja afetado pelas operações do empreendimento. Portanto, um stakeholder pode ser tanto os acionistas como os funcionários. A empresa que ignora as influências dos grupos não obterá sucesso, podendo até chegar à falência (TAPSCOTT; TICOLL, 2005).

Gonzaga reconheceu que o conceito de sustentabilidade estava:

[...] enraizado nos funcionários por que no programa de ideias muitas ideias são sobre ações para reduzir o impacto, ações de sustentabilidade. Então, a gente vê que isso está bem enraizado uma vez que os funcionários sugerem sempre alguma atividade desse tipo".

Coutinho, a camareira, mencionou acreditar que seu trabalho era importante para o hotel. Ela afirmou que não só o trabalho dela, como o de todos, fazia a diferença. No entanto, Silva revelou que, muitas vezes, por motivos pessoais até, incentivar os funcionários a trabalharem as práticas dos hotéis acabava se tornando uma tarefa difícil. 
Não é fácil, é trabalho de formiguinha, a gente fala, fala, fala e fala, enfim, todo mundo sabe que precisa ser feito, mas na prática não se faz. A gente procura sempre fazer ações internas, a gente procura fazer com que eles se envolvam, mas não é fácil, se eu te disser hoje que todos os colaboradores estão engajados, na verdade nem a metade, infelizmente (SILVA).

Bettini também reforçou o papel da associação com o hotel:

[...] diante desse cenário a gente encara que a associação tem sim um papel chave em trazer esse conhecimento, em tentar elevar esse patamar de conhecimento dos associados sobre o que é possível fazer em relação ao tema e acabar um pouquinho com o estigma de que ser sustentável é só ser bonitinho, sustentabilidade é só marketing.

Ela ainda reforçou que "a gente, cada vez mais, tenta mostrar que ser sustentável também pode ser mais barato, pode trazer economia, que normalmente é o que tem mais efeito junto aos nossos associados". Afirmou, também, que a sustentabilidade era uma tendência, além de ser essencial. Então, seu papel, enquanto associação era de levar os hotéis a chegarem ao patamar que economias mais evoluídas já haviam chegado trabalhando a sustentabilidade (BETTINI).

Quando se trata do relacionamento com os fornecedores, Araújo afirmou que o Pullman procurava beneficiar os que trabalhavam de forma correta. E, de acordo, Miranda declarou que:

[...] os nossos amenities, eles precisam ser ecológicos, todos os amenities, os produtos de limpeza, nós compramos de um fornecedor que também tem a ISO 14000, assim como a gente, então todo o processo de compra de amenities, de produtos de limpeza, que são produtos que podem deteriorar, enfim, eles precisam ter um embasamento assim como a Accor tem.

Em contrapartida, percebeu-se também a procura das empresas por hotéis corretos para parcerias, conforme relata Gonzaga:

Empresa, se ela tem uma estratégia de sustentabilidade muito forte e ela tem um processo de avaliação de fornecedor que inclui a sustentabilidade, aí eu acho que sim entra na classificação na escolha de um fornecedor, até hotéis que tenham algum tipo de estratégia.

Araújo ainda afirmou que "se ele [o cliente] quer vir aqui ver tudo e pede documentação, ele realmente está preocupado que aquilo seja uma verdade". 
O relacionamento com o hóspede para o cumprimento das ações estava se dando, normalmente, a partir de comunicados visuais, conforme depoimento de Batista.

\begin{abstract}
Com o hóspede a gente tenta formas de comunicações mais simples possíveis [...] e quando ele faz a comunicação visual com aquele folder e ele consegue verificar que se ele não quiser descartar o seu material, pode deixar [...] já é uma forma de fazer um incentivo sobre a questão de sustentabilidade e reverter isso para gente em custo.
\end{abstract}

Coutinho mencionou perceber no seu dia a dia que os hóspedes estavam engajados e achavam importantes as ações do hotel, escolhendo não trocar sua toalha e seu enxoval, por exemplo. Outro fato que estava indicando esse engajamento dos hóspedes, de acordo com Bettini e Gonzaga, era o fato de o site TripAdivisor disponibilizar um selo de "hotel sustentável", concedido após o cumprimento de um questionário.

Portanto, a identificação de cada um dos grupos de stakeholder é importante para saber qual é a melhor maneira de se trabalhar com eles.

\title{
5.3 PROPOSIÇÃO 3: A HOSPITALIDADE CONTRIBUI NA RELAÇÃO POSITIVA COM OS STAKEHOLDERS
}

Esta proposição foi ratificada. De acordo com as entrevistas, pôde-se confirmar que a hospitalidade oferecida aos stakeholders estava contribuindo para a relação de troca entre eles e o hotel.

De acordo com Bekin (2004), as empresas que melhor satisfazem seus funcionários têm maiores chances de os terem trabalhando de maneira eficaz. Segundo Guerrier e Adib (2004), o comportamento dos colaboradores parte da percepção do tratamento que eles recebem de seus superiores e também dos clientes com quem têm contato.

Gonzaga afirmou que "o funcionário tem que estar feliz, tem que estar satisfeito, ele tem que trabalhar num bom ambiente para ele ter a pré-disposição e ele estar bem para oferecer esse bom atendimento para o cliente, nesse caso". Araújo mencionou acreditar que "qualquer tipo de relacionamento precisa ter empatia. Nós tratamos as pessoas e esse tratamento volta para a gente".

E a governanta Miranda disse que: 
[...] o que elas recebem, elas vão repassar, ao certo. [...] E elas precisam entender o porquê das coisas, não adianta só falar que a gente vai reciclar, porque tem que reciclar, porque elas não vão fazer, elas têm que vestir a camisa e comprar a causa, é entender o que tem que fazer e fazer.

E, ainda, sustentou que:

[...] a forma como a gente fala, tem que ter um perfil voltado para esse público, conforme o perfil delas, porque não deixa de ser uma cadeia mesmo, porque o que elas recebem é o que elas vão passar para o hóspede. Embora elas não falem a grande maioria não sejam bilíngues, elas se comunicam muito bem com qualquer hóspede que fale qualquer língua que seja e elas repassam essas informações.

Esta ideia que é reforçada por Albrecht (1994), para quem a qualidade dos serviços prestados é um grande diferencial, e seu sucesso não depende de só uma pessoa, mas sim de todos os funcionários, que, trabalhando em conjunto, podem atender e satisfazer os clientes, além de ser um fator importantíssimo para alcançar as metas de uma organização.

Gonzaga narrou que "se a gente pensa em fornecedores é um pouquinho diferente, mas eu já ouvi comentários de 'Ah! É tão bom trabalhar com comprador de hotel porque vocês são muito mais simpáticos. Tem lugar que trata a gente que nem lixo"”.

De acordo com Vieira e Hoffmann (2007), os hotéis estão propensos a maiores desperdícios, uma vez que o consumo não é controlado apenas pelos gestores, mas também pelos hóspedes, funcionários etc. Portanto, um dos fatores fundamentais a ser trabalhado é a mudança de atitude das pessoas. Com isso, Batista afirmou: "hoje em dia, para a gente ter um hotel sustentável, a gente tem que começar do básico, do colaborador, quando ele entra. Tem que ser uma das primeiras premissas a serem abordadas". E reforçou: "a gente começa a educar o colaborador, desde que ele entra, envolvendo eles nas ações e depois isso vai aumentando". Por fim, acrescentou:

[...] quando a gente faz o processo de aprovação para a pessoa fazer parte do nosso quadro de funcionários, a gente tem o acolhimento, a gente fala toda a história da rede, além de falar as funções da pessoa, é falado o histórico dos outros hotéis e tem uma parte que a gente fala exclusivamente sobre sustentabilidade, porque isso, na verdade, está explícito na missão da rede. 
Coutinho explicou como estava ocorrendo no Intercontinental: "Todas que entram passam por um treinamento de reciclagem e isso é feito no terceiro andar. $\mathrm{E}$ quando uma nova camareira entra, já fica com uma camareira mais experiente que dá esse treinamento completo para ela".

\section{CONSIDERAÇÕES FINAIS}

Muitos hotéis se utilizam de práticas voltadas à sustentabilidade e trabalham os fatores ambientais, sociais e econômicos em conjunto, com o intuito de atingir seus resultados e metas. Grandes redes de hotéis possuem programas voltados unicamente à gestão desses fatores e buscam suprir não somente as necessidades globais, mas também suas necessidades enquanto uma organização.

Nesta pesquisa se teve por objetivo geral apresentar a importância de uma gestão sustentável em hotéis, visando ao equilíbrio entre os fatores ambientais, sociais e econômicos para o sucesso de um empreendimento, considerando a hospitalidade na relação com stakeholders para tal. Tal objetivo foi alcançado. Os gestores alegaram que trabalhar a sustentabilidade estava sendo imprescindível para todos os hotéis.

A partir do objetivo geral, foram elaborados três objetivos específicos para esta pesquisa, para melhor conduzi-la. O primeiro objetivo específico - "examinar como se dava essa gestão sustentável em hotéis" - foi alcançado. Os três hotéis escolhidos para estudos possuíam programas voltados à responsabilidade coorporativa. Todos os depoimentos apresentaram como o conceito estava sendo trabalhado nos hotéis.

No hotel Intercontinental São Paulo, a gestão sustentável estava acontecendo por meio da ferramenta chamada Green Engage. A ferramenta, que é validada pelo programa Leadership in Energy and Environmental Design (LEED), conta com um checklist de atividades que orienta os gestores dos hotéis a darem início as ações. Então, a ferramenta indica onde se pode reduzir consumo, emissão etc., além de dar sugestões de atividades que ajudam o aprimoramento dos processos.

Cada departamento ainda estava trabalhando com uma ferramenta chamada "Roda", que possui os quadrantes Retorno financeiro, Nossa gente, Experiência do hóspede e Empresa responsável. Assim, todos têm a responsabilidade de trabalhar 
também com ações sustentáveis, pois eles são avaliados e medidos com base nesta ferramenta.

No Pullman São Paulo Ibirapuera, a gestão sustentável estava acontecendo por meio dos programas da rede Accor, o Planet 21 e o programa Plant for the Planet. O programa Planet 21 era trabalhado nos hotéis a partir dos eixos de saúde, natureza, carbono, emprego, local, inovação e diálogo. Já o programa Plant for the Planet consiste em uma ação de reflorestamento.

O hotel Meliá Jardim Europa estava trabalhando com a gestão sustentável baseada nas ações que eram designadas pelo coorporativo da rede. Entretanto, reforçaram que trabalhavam com ações individuais também, a critério de cada unidade. Com os funcionários a sustentabilidade era trabalhada desde sua entrada no hotel.

O segundo objetivo específico - "analisar a importância dos stakeholders para esta gestão" - também foi alcançado. Um fato muito comentado nos depoimentos coletados indicou o engajamento dos funcionários com as ações propostas pelos hotéis. Uma vez que são eles que têm o contato direto com os hóspedes, se fazia importante têlos trabalhando com a estratégia da empresa.

Outro stakeholder importante percebido durante a coleta de dados foi o fornecedor. Este, na maioria das vezes, era escolhido a partir da verificação se sua estratégia estivesse de acordo com a estratégia dos hotéis. Por exemplo, no Meliá a escolha do fornecedor para os amenities do greenfloor foi o fato de a empresa oferecer um produto ecologicamente correto, com as embalagens reutilizadas, ser uma empresa local e, assim, gerar menos impacto com transporte do produto. No Pullman a empresa de retirada do lixo possuía certificações que comprovavam a destinação correta do que era descartado. Dessa maneira, foi possível perceber que, a escolha do fornecedor nos hotéis que trabalhavam a sustentabilidade era importante, pois era preciso garantir que a sua relação com eles não fosse contra a sua estratégia sustentável.

O terceiro objetivo específico - "avaliar como a hospitalidade influencia na relação entre as partes" - também foi alcançado. Considerou-se que o funcionário, enquanto um stakeholder, iria trabalhar num bom ambiente para executar suas funções corretamente e oferecer um bom atendimento aos clientes. Para isso, deveria estar feliz e satisfeito. 
Assim, a problemática "Por que os quesitos ambientais, sociais e econômicos seriam importantes para a gestão de um hotel?" pôde ser respondida. Em conformidade com as proposições, considerou-se ter ficado claro a importância de se trabalhar esses fatores na atualidade.

Vista como grande tendência, a sustentabilidade pode trazer aos empreendimentos resultados financeiros, engajamento dos funcionários, aprimoramento no relacionamento com fornecedores, parcerias com ONGs etc., além de grande vantagem competitiva para com seus concorrentes, dado que, cada vez mais, grandes empresas e clientes individuais têm essa consciência e buscam a compra de produtos ecologicamente corretos e serviços que não tenham grande impacto no meio ambiente e que trabalham em benefício da sociedade.

Posto isso, recomenda-se que os hotéis busquem, cada vez mais, aprimorar a prática de ações sustentáveis em sua operação, visto que, em conformidade com os dados obtidos durante o estudo de casos, tais práticas podem trazer inúmeros resultados positivos para o empreendimento.

\section{REFERÊNCIAS}

ABREU, V. A. A Máquina da hospitalidade. In: DENCKER, A. F. M.; BUENO, M. S. (Org.). Hospitalidade: cenários e oportunidades. São Paulo: Pioneira Thomson Learning, 2003.

ALBRECHT, K. Revolução nos serviços: como as empresas podem revolucionar a maneira de tratar seus clientes. São Paulo: Pioneira, 1994.

ANDRADE, J. M. R. Sustentabilidade empresarial: um estudo exploratório nas empresas hoteleiras da região metropolitana de Natal/RN. 2012. 113 f. Dissertação (Mestrado em Ciências Contábeis) - Universidade de Brasília, Universidade Federal da Paraíba, Universidade Federal do Rio Grande do Norte, Natal, 2012. Disponível em: <http://repositorio.unb.br/handle/10482/11470>. Acesso em: 18/09/2015.

BARDIN, L. Análise de conteúdo: Lisboa: Edições 70, 1977. Disponível em: <http://pt.slideshare.net/RonanTocafundo/bardin-laurence-anlise-de-contedo>. Acesso em: 26/6/2015.

BEKIN, S. F. Endomarking: como praticá-lo com sucesso. São Paulo: Prentice Hall, 2004. 
CABRERA, L. C. Afinal, o que é sustentabilidade. 2009. Disponível em: $<$ http://planetasustentavel.abril.com.br/noticia/desenvolvimento/conteudo_474382.shtm 1>. Acesso em: 09/06/2015.

CAMARGO, L. O. L. Hospitalidade. 2. ed. São Paulo: Aleph, 2004.

ClARO, P. B. O.; CLARO, D. P.; AMÂNCIO, R. Entendendo o conceito de sustentabilidade nas organizações. R. Adm., São Paulo, v. 43, n. 4, p. 289-300, 2008. Disponível em: <http://www.rausp.usp.br/busca/artigo.asp?num_artigo=1354> Acesso em: 25/08/2015.

CLARKSON, M. B. E. A stakeholder framework for analyzing and evaluating corporation. Academy of Management Review. v. 20, n. 1, p. 92-117, 1995.

FREEMAN, R. E. Strategic management: a stakeholders approach. Massachusetts: Pitman, 1984.

GONÇALVES, L. C. Gestão Ambiental em meio de hospedagem. 1. ed. São Paulo: Aleph, 2004.

GUERRIER, Y.; ADIB, A. O trabalho na indústria da hospitalidade. In: LASHLEY C.; MORRISON, A. (Org.). Em busca da hospitalidade. São Paulo: Manole, 2004. P. 357-386.

GUIZI, A. A.; SANTOS, A. F. L.; WADA, E. K. (2014). Hotelaria e stakeholders: competitividade em eventos corporativos - Estudo de caso sobre a rede Bourbon de Hotéis e Resorts. In: SEMINÁRIO DA ASSOCIAÇÃO NACIONAL PESQUISA E PÓS-GRADUAÇÃO EM TURISMO - ANPTUR, 11., Fortaleza. Anais... Disponível em:

<http://www.anptur.org.br/novo_portal/anais_anptur/anais_2014/arquivos/DHT/DHT1/ 084.pdf>. Acesso em: 25/08/2015.

KOGA, E. S.; WADA, E. K. Análise dos stakeholders e gestão dos meios de hospedagem: estudo de casos múltiplos na Vila do Abraão, Ilha Grande, RJ1. Turismo em Análise, v. 24, n. 1. 2013.

LASHLEY, C.; MORRISON, A. (Org.). Em busca da hospitalidade: perspectivas para um mundo globalizado. Barueri: Manole, 2004.

LYRA, M. G.; GOMES R. C.; JACOVINE L. A. G. O papel dos stakeholders na sustentabilidade da empresa: contribuições para construção de um modelo de análise. Anpad, v. 13, jun. Edição Especial, 2009 Disponível em: <http://www.scielo.br/pdf/rac/v13nspe/a04v13nspe.pdf>. Acesso em: 09/06/2015.

PERES, M. R.; REZENDE, D. C. Gestão da sustentabilidade no segmento hoteleiro: estudo dos meios de hospedagem de Monte Verde, MG. Caderno Virtual de Turismo. Rio de Janeiro, v. 11, n. 2, p. 234-252, ago. 2011. 
QUADROS, A. H. A hospitalidade e o diferencial competitivo das empresas prestadoras de serviços. Revista Hospitalidade, São Paulo, v. 8, n. 1, 2011.

SEBRAE. Serviço de Brasileiro de Apoio às Micro e Pequenas Empresas. Princípios da qualidade. 2 ed. Porto Alegre: SEBRAE, 2000. v. 1.

SEIFFERT, M. E. ISO 14001: Sistemas de Gestão Ambiental. Implantação objetiva e econômica. 3. ed. São Paulo: Atlas, 2007.

SILVA, J. C. Hospitalidade na hotelaria. 2012. Disponível em: $<$ http://www.portaleducacao.com.br/turismo-e-hotelaria/artigos/19153/a-hospitalidadena-hotelaria\#!1>. Acesso em: 23/05/2015.

TAPSCOTT, D.; TICOLL, D. A empresa transparente. São Paulo: M. Books do Brasil, 2005.

VIEIRA, D. G. Qualidade na prestação de serviços: um estudo de caso na Organização Contábil Garcia LTDA. 2007. 122 f. Monografias (Bacharel) - Curso de Administração, Universidade do Vale do Itajaí, Balneário Camboriú, 2007.

VIEIRA, E.; HOFFMANN, V. Práticas de sustentabilidade ambiental para empreendimentos turísticos hoteleiros: aplicação de um modelo. SEMINTUR, 4.,. Caxias do Sul. Anais... Universidade Caxias do Sul, 2007. Disponível em: <http://www.ucs.br/ucs/tplSemMenus/eventos/seminarios_semintur/semin_tur_4/gt12>. Acesso em 23/8/2015.

YASSUDA, M. H. Gestão ambiental em hotel urbano: estudo de caso: Meliá Jardim Europa. 2004. 200 f. Dissertação (Mestrado) - Curso de Hospitalidade, Universidade Anhembi Morumbi, São Paulo, 2004.

YIN, R. K. Estudo de casos: planejamento e métodos. 3. ed. Porto Alegre: Bookman, 2005.

Recebido em: 18-07-2106.

Aprovado em: 17-06-2016. 